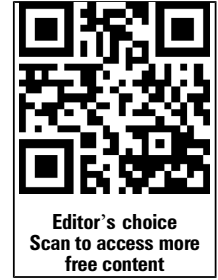

Handling editor Tore K Kvien

- Additional material is published online only. To view please visit the journal online (http://dx.doi.org/10.1136/ annrheumdis-2014-205696)

${ }^{1}$ Division of Rheumatology, Allergy and Immunology, UC San Diego School of Medicine, La Jolla, California, USA

${ }^{2}$ Laboratory of Gene Regulation and Signal Transduction, UC

San Diego School of Medicine, La Jolla, California, USA

${ }^{3}$ Departments of

Pharmacology, UC San Diego

School of Medicine, La Jolla,

California, USA

${ }^{4}$ Pathology, UC San Diego

School of Medicine, La Jolla,

California, USA

${ }^{5}$ Department of Nutritional

Sciences \& Dell Pediatric

Research Institute, University of Texas at Austin, Austin, Texas, USA

${ }^{6}$ Division of Translational Oncology, Health Research Institute and University Hospital "Fundación Jiménez Díaz", Madrid, Spain

\section{Correspondance to} Dr Monica Guma, Division of Rheumatology, Allergy and Immunology, UCSD School of Medicine, 9500 Gilman Drive, La Jolla, CA 92093-0656, USA; mguma@ucsd.edu

Received 7 April 2014 Revised 28 July 2014 Accepted 13 September 2014

Published Online First

1 October 2014
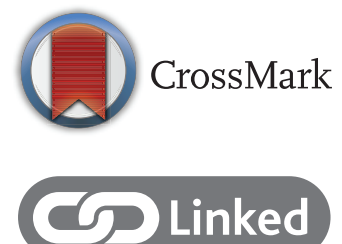

http://dx.doi.org/10.1136/ annrheumdis-2014-206618

To cite: Guma M, SanchezLopez E, Lodi A, et al. Ann Rheum Dis 2015;74

1399-1407.

\title{
Choline kinase inhibition in rheumatoid arthritis
}

\author{
M Guma, ${ }^{1}$ E Sanchez-Lopez, ${ }^{2,3,4}$ A Lodi, $^{5}$ R Garcia-Carbonell, ${ }^{2,3,4}$ S Tiziani, $^{5}$ \\ M Karin, ${ }^{2,3,4}$ J C Lacal, $^{6}$ G S Firestein ${ }^{1}$
}

\section{ABSTRACT}

Objectives Little is known about targeting the metabolome in non-cancer conditions. Choline kinase (ChoK $\alpha$ ), an essential enzyme for phosphatidylcholine biosynthesis, is required for cell proliferation and has been implicated in cancer invasiveness. Aggressive behaviour of fibroblast-like synoviocytes (FLS) in rheumatoid arthritis (RA) led us to evaluate whether this metabolic pathway could play a role in RA FLS function and joint damage.

Methods Choline metabolic profile of FLS cells was determined by ${ }^{1} \mathrm{H}$ magnetic resonance spectroscopy ('HMRS) under conditions of ChoK $\alpha$ inhibition. FLS function was evaluated using the ChoK $\alpha$ inhibitor MN58b $\left(I_{50}=4.2 \mu \mathrm{M}\right)$. For arthritis experiments, mice were injected with $\mathrm{K} / \mathrm{BxN}$ sera. MN58b (3 mg/kg) was injected daily intraperitoneal beginning on day 0 or day 4 after serum administration.

Results The enzyme is expressed in synovial tissue and in cultured RA FLS. Tumour necrosis factor (TNF) and platelet-derived growth factor (PDGF) stimulation increased ChoK $\alpha$ expression and levels of phosphocholine in FLS measured by Western Blot (WB) and metabolomic studies of choline-containing compounds in cultured RA FLS extracts respectively, suggesting activation of this pathway in RA synovial environment. A ChoK $\alpha$ inhibitor also suppressed the behaviour of cultured FLS, including cell migration and resistance to apoptosis, which might contribute to cartilage destruction in RA. In a passive $\mathrm{K} / \mathrm{BxN}$ arthritis model, pharmacologic ChoKa inhibition significantly decreased arthritis in pretreatment protocols as well as in established disease.

Conclusions These data suggest that ChoK $\alpha$ inhibition could be an effective strategy in inflammatory arthritis. It also suggests that targeting the metabolome can be a new treatment strategy in non-cancer conditions.

\section{INTRODUCTION}

Synovial inflammation, hyperplasia and joint destruction are hallmarks of rheumatoid arthritis (RA). ${ }^{1}$ Resident fibroblast-like synoviocytes (FLS) contribute to synovial inflammation by producing inflammatory mediators and recruiting and activating immune cells. ${ }^{2}{ }^{3}$ FLS in the intimal lining and pannus are the major effectors of cartilage damage through production of extracellular matrixdegrading enzymes, such as metalloproteinases (MMP) and cathepsins. $^{2-4}$ New targeted and rationally designed disease-modifying agents that modify FLS behaviour are needed to complement current therapies. However, the molecular mechanisms that regulate FLS behaviour in RA are poorly understood and represent a major obstacle for developing therapeutic interventions that modulate these functions.

Metabolomics provides a global assessment of a cellular state within the context of its immediate environment, taking into account genetic regulation, altered kinetic activity of enzymes, and changes in metabolic pathways. ${ }^{5} \mathrm{~A}$ metabolomic strategy might provide insights that define mechanisms underlying disease, and permit development of new treatment strategies. However, few studies have addressed metabolic changes in RA, ${ }^{6-10}$ and none specifically in FLS.

In oncology, the tumour metabolome is beginning to be characterised, and such studies have already suggested several new targets and biomarkers. ${ }^{11-13}$ Among other changes, tumours display elevated phospholipid levels characterised by increases in the levels of phosphocholine (PCho) and total cholinecontaining metabolites (tCho) together with decreases in the glycerophosphocholine (GPC)/ PCho ratio. ${ }^{14-17}$ Elevated PCho levels are partially attributed to increased activity of $\mathrm{ChoK} \alpha$, the enzyme that catalyses the first step in CDP-choline pathway and is essential for phosphatidylcholine (PtdCho) biosynthesis, ${ }^{18}$ the major phospholipid in eukaryotic membranes that is also required for the increased cancer cell proliferation, tumour progression and invasion. ${ }^{14}{ }^{19}$ High levels of ChoKa expression and activity are often associated with malignant transformation, invasion and metastasis in some human cancers. Thus, this enzyme was recently proposed as a new target for cancer therapy ${ }^{1820}$ and has been recognised as a prognostic marker in various human cancers. ${ }^{14}{ }^{21-24}$ However, very little is known about $\mathrm{ChoK} \alpha$ role in other noncancer cells and diseases. ${ }^{25-29}$

Mitogen-activated protein kinase (MAPK) and phosphoinositide 3-kinase (PI3K)/Akt are signalling pathways that regulate FLS function in RA, including effects on MMP expression and synoviocyte growth and survival. Of interest, selective inhibition of choline kinase attenuates MAPK and PI3K/Akt signalling. ${ }^{30} 31$ These considerations led us to perform an assessment of choline metabolism in RA FLS to determine if the ChoKo activity regulates their pathogenic behaviour and to determine the suitability of ChoK $\alpha$ as a therapeutic target.

\section{RESULTS \\ ChoKa expression and choline metabolite profile in RA synovium}

We initially determined ChoK $\alpha$ protein expression in synovial tissues using immunohistochemistry. ChoK $\alpha$ is highly expressed in osteoarthritis (OA) and RA synovium (figure 1A-C) with especially 
A

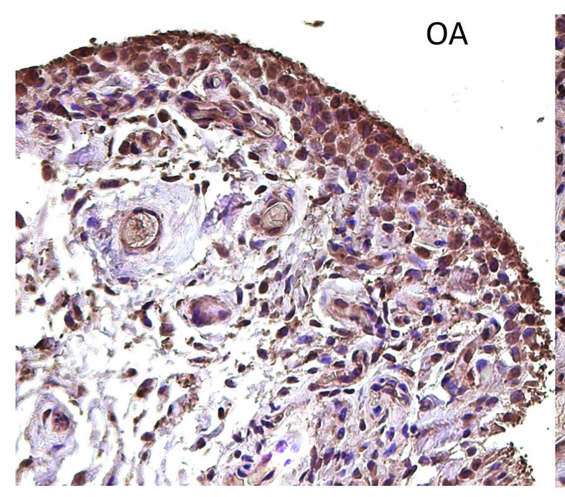

D
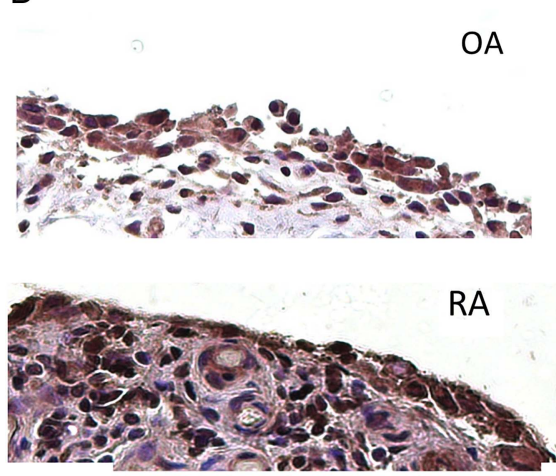

G

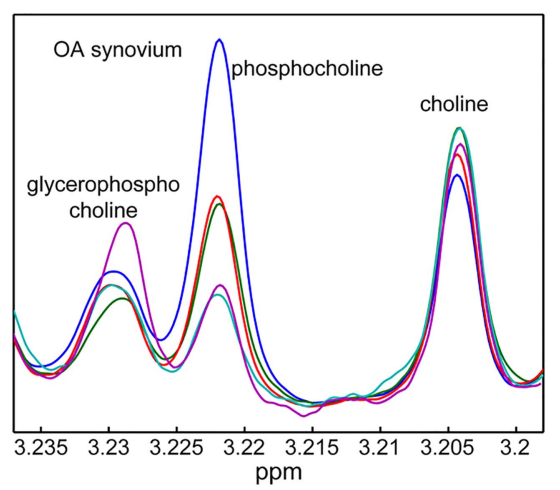

B

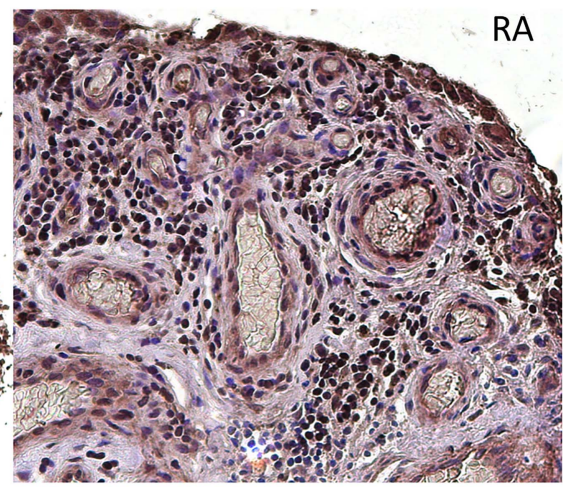

E

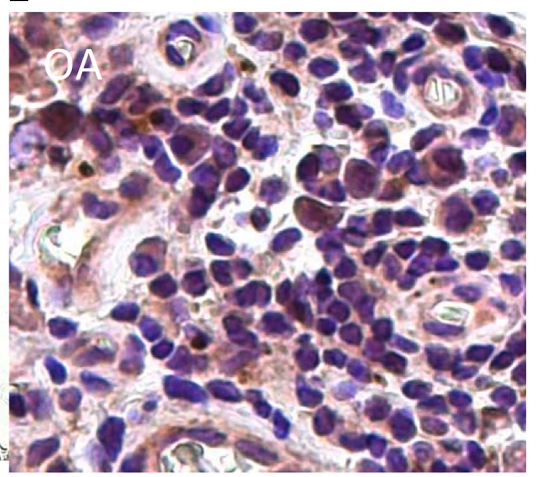

$\mathrm{H}$

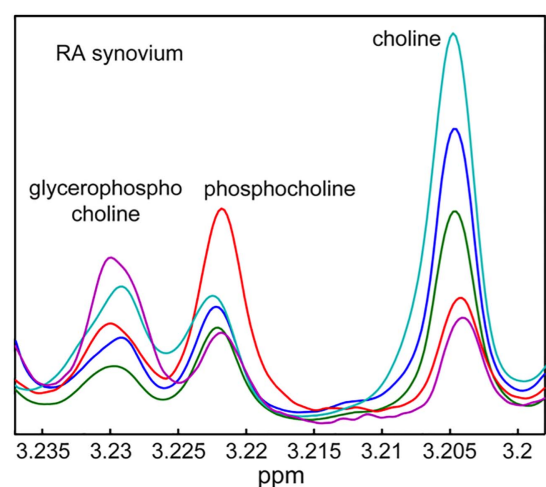

C

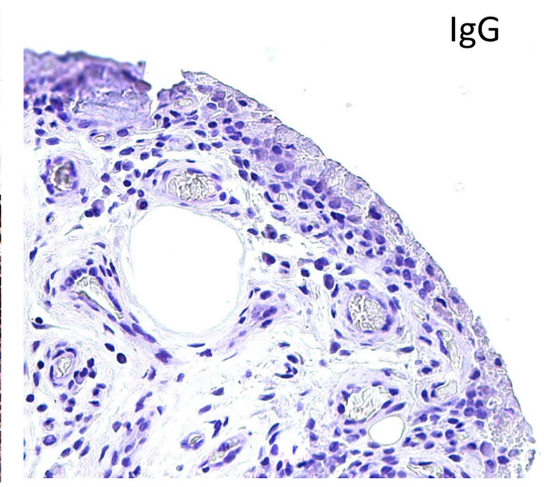

$\mathrm{F}$

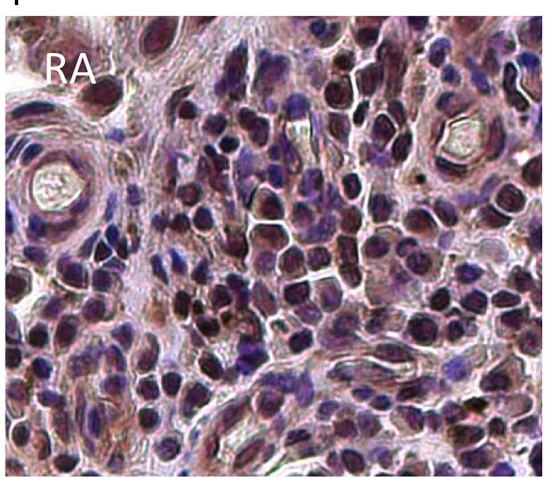

।

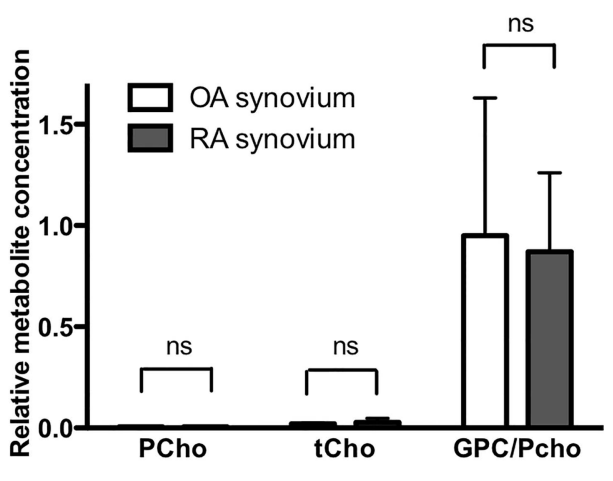

Figure 1 Choline kinase (ChoK $\alpha$ ) expression in arthritic synovium. Osteoarthritis (OA) (A) and rheumatoid arthritis (RA) synovium (B) were immunostained with a ChoK $\alpha$ antibody. IgG was used as a negative control (C). (D) High magnification of ChoK $\alpha$ immunostatining showing a homogeneous staining in intimal lining in both OA and RA synovium sample. (E and F) ChoKo immunostaining of sublining in an OA (E) and RA (F) synovium sample. ( $\mathrm{G}$ and $\mathrm{H}$ ) methyl proton resonances of Cho-containing metabolites ('HMRS spectral region 3.20-3.24 ppm) and (I) quantification of choline-containing metabolites from $5 \mathrm{OA}$ and 5 RA synovium samples and glycerophosphocholine (GPC/PCho) ratio. ${ }^{\mathrm{H}} \mathrm{HMRS},{ }^{1} \mathrm{H}$ magnetic resonance spectroscopy.

prominent staining in the synovial intimal lining (figure 1D) although infiltrating cells in the sublining were also positive in some samples (figure 1E, F). The initial metabolomics profile of the synovium was determined using ${ }^{1} \mathrm{H}$ magnetic resonance spectroscopy ( ${ }^{1}$ HMRS). Some RA samples clearly showed very high total choline-containing metabolites, but overall PCho levels and choline metabolite profiles of the whole RA and OA synovia were not significantly different (figure 1G-I).

\section{ChoKa expression and activity in RA fibroblast-like synoviocytes}

Because ChoK $\alpha$ was highly expressed in intimal lining cells, we evaluated its expression and regulation in cultured primary FLS. Expression of ChoKa was confirmed by Western Blot (WB) analysis ( $\mathrm{n}=5$ per group) (figure 2A), with similar levels in RA and
OA cell lines. To determine relative levels of enzyme activity in $\mathrm{OA}$ and RA cell lines, we used ${ }^{1}$ HMRS to detect cholinecontaining compounds profile in cell extracts. Interestingly, the MRS spectra of these metabolites were similar to tumour cells, which display elevated phospholipid levels characterised by increases in PCho and total choline-containing metabolites together with a decrease in the GPC/PCho ratio $<1$ (a phenomenon known as the 'GPC-to-PCho switch'). ${ }^{32}$ In RA and OA FLS, PCho was the predominant metabolite and the GPC/PC ratio was $<1$, suggesting that ChoK $\alpha$ is active in FLS cell lines (figure 2B). Although a few RA FLS showed higher PCho levels than OA FLS (figure 2B), choline-containing metabolites were similar in OA and RA FLS (figure 2C). We also determined if normal FLS and normal primary fibroblasts from other tissues had ChoK $\alpha$ activity similar to OA/RA FLS. Although we could 
A
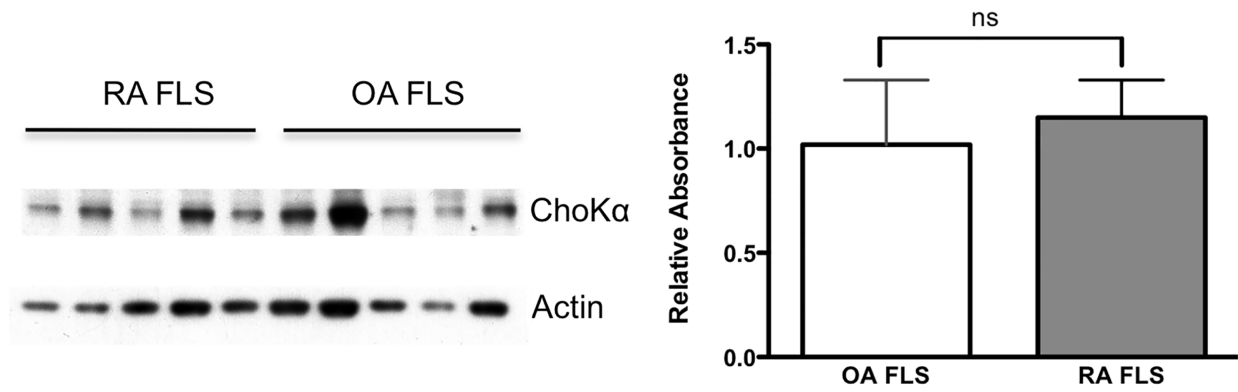

B

C
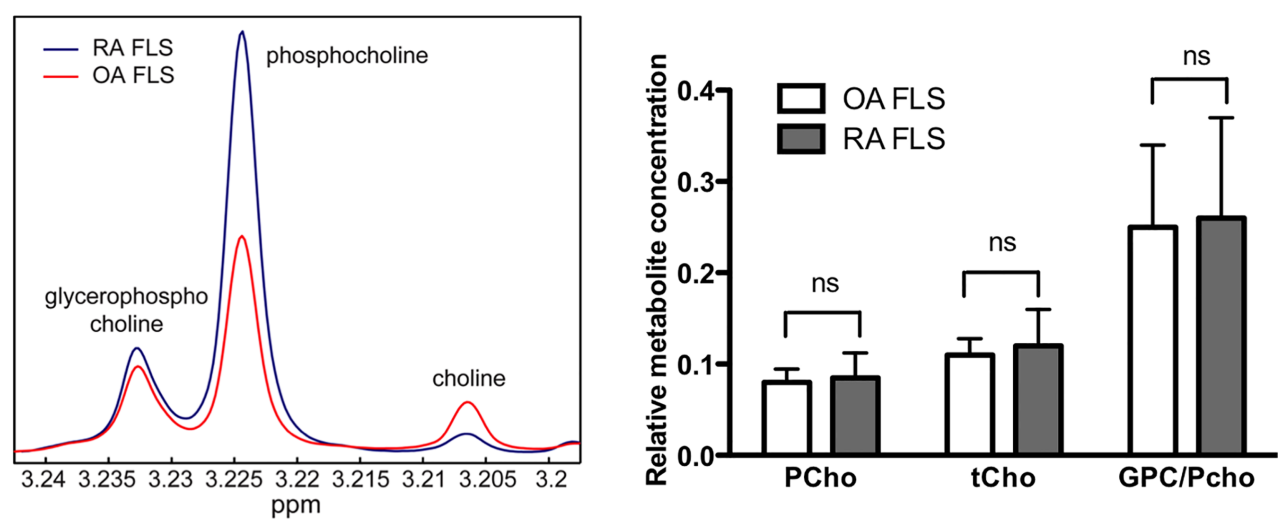

D
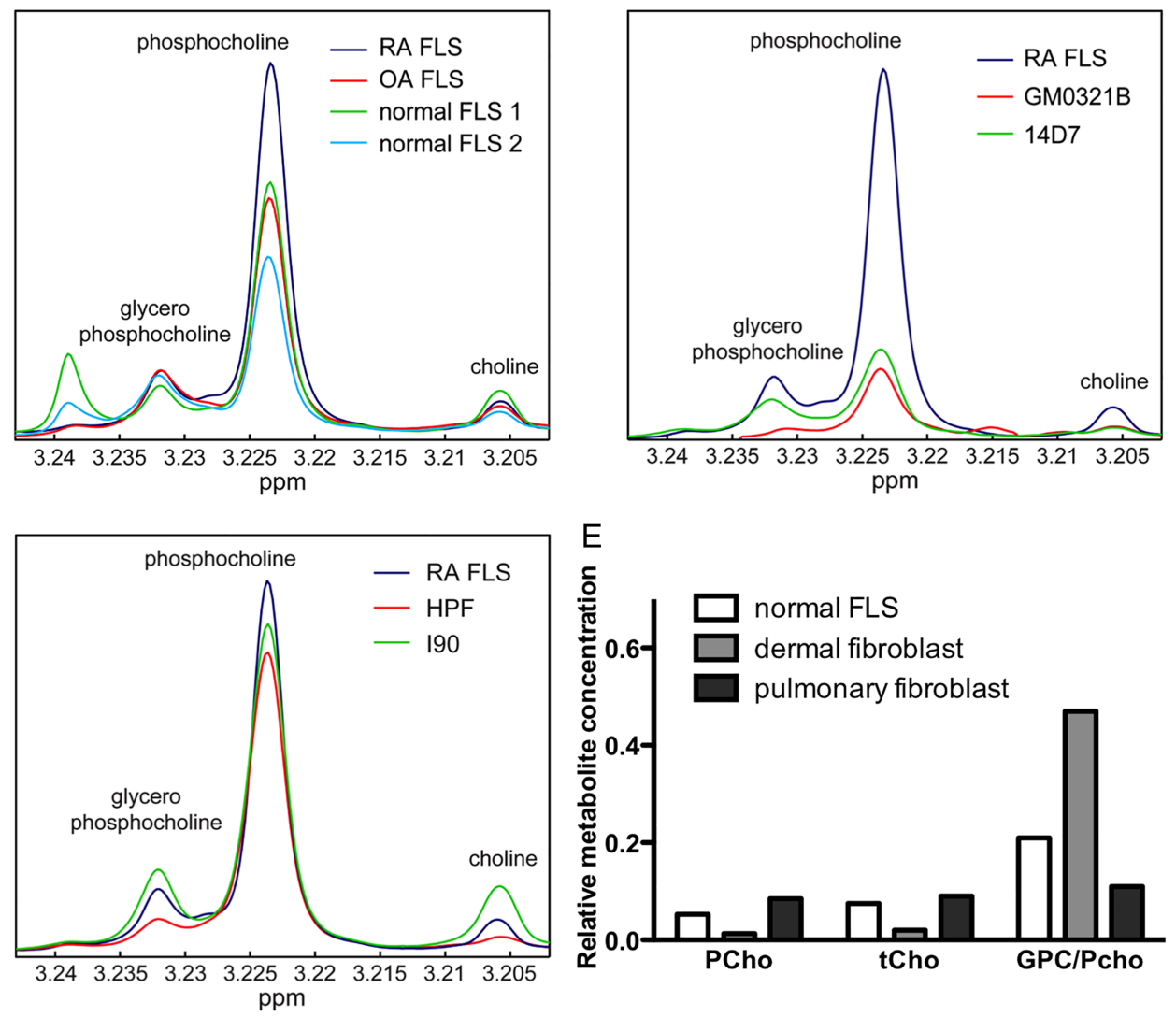

Figure 2 Choline kinase (ChoK $\alpha$ ) expression in fibroblast-like synoviocytes (FLS). (A) ChoK $\alpha$ expression in 5 osteoarthritis (OA) and 5 rheumatoid arthritis (RA) FLS by WB and quantification. (B) ${ }^{1}$ HMRS spectra of choline-containing metabolites from 1 representative RA and 1 OA FLS samples. (C) Quantification of choline-containing metabolites from RA and OA FLS samples $(n=10)$. (D) ${ }^{1} \mathrm{HMRS}$ spectra of choline-containing metabolites (methyl proton resonances) from normal primary fibroblast: 14D7 and GM0321 are dermal fibroblasts; HPF and 190 are pulmonary fibroblasts. (E) Representative choline-containing metabolites profile from normal primary fibroblasts. ${ }^{1} \mathrm{HMRS},{ }^{1} \mathrm{H}$ magnetic resonance spectroscopy; HPF, human pulmonary fibroblasts; WB, Western Blot. 
only evaluate a limited number of those cell lines, PCho was also the predominant metabolite in normal FLS and pulmonary fibroblasts but not in dermal fibroblast (figure 2D, E). Thus, our data suggests that ChoK $\alpha$ activity varies between normal primary fibroblasts, and might regulate fibroblast functions in other types of fibroblasts such as pulmonary primary fibroblasts.

\section{Effect of inflammatory mediators on ChoKa}

To determine whether inflammatory mediators implicated in RA regulate ChoK $\alpha$ expression, we stimulated RA FLS with tumour necrosis factor (TNF), interleukin-1 $\beta$ (IL-1), platelet-derived growth factor (PDGF), epithelial growth factor (EGF) or lipopolysaccharide (LPS) for $36 \mathrm{~h}$ and assayed ChoK $\alpha$ protein by WB. ChoK $\alpha$ expression increased 2-fold after TNF, IL-1, PDGF or EGF stimulation, whereas LPS had no effect (figure 3A). Both PDGF and TNF increased PCho levels, but only PDGF decreased the GPC/PCho ratio, suggesting a more specific increase of ChoK $\alpha$ activity after PDGF exposure, whereas TNF might also activate other metabolic pathways, such as PtdCho degradation via phospholipase (PL) A2 and phospholipase B (PLB) which would increase the levels of GPC and, as a consequence, the GPC/Pcho ratio remains constant (figure 3B-D).

\section{Effect of ChoKa inhibition on FLS function}

To determine if the choline metabolite profile in FLS is secondary to ChoK $\alpha$ activation, we used ${ }^{1}$ HMRS in the presence or absence of a ChoK $\alpha$ inhibitor. The selective competitive ChoK $\alpha$ inhibitor, MN58b, was used in these and other
A

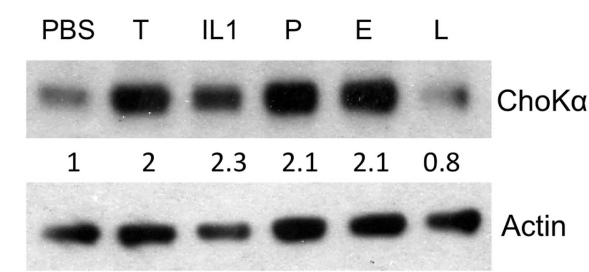

D

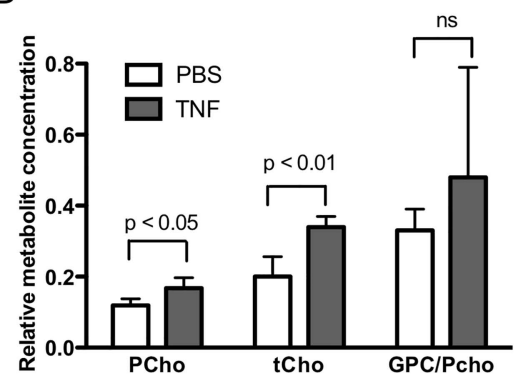

G

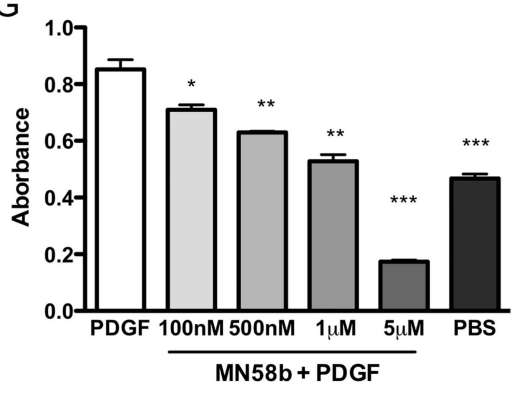

B

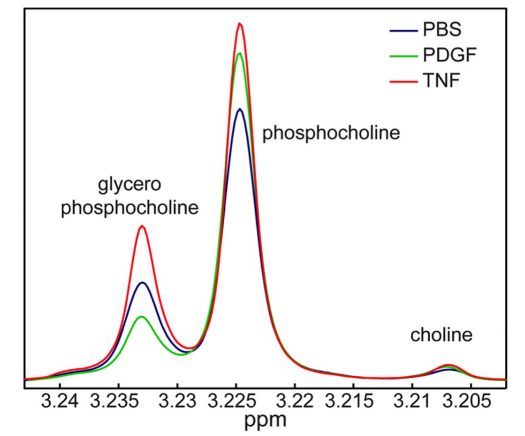

E

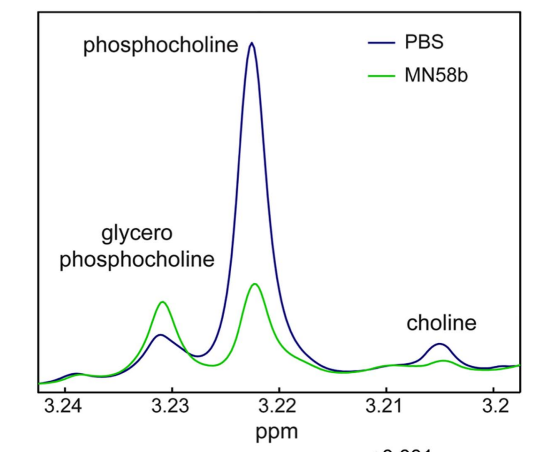

$\mathrm{H}$

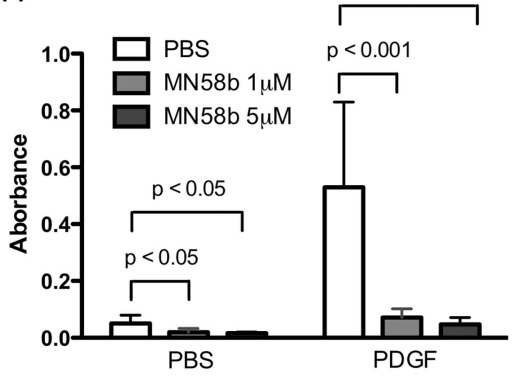

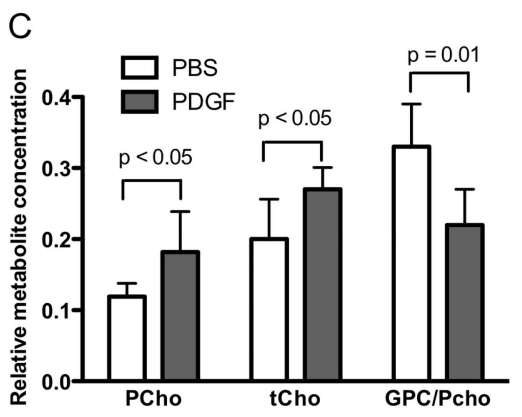
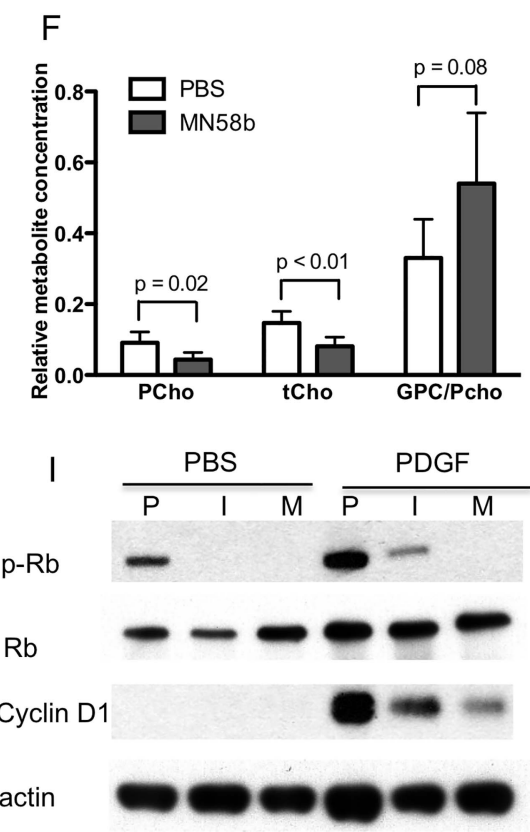

Figure 3 Choline kinase (ChoK $\alpha$ ) regulation in fibroblast-like synoviocytes (FLS) and effect of ChoK $\alpha$ inhibition on platelet derived growth factor (PDGF)-mediated FLS growth. (A) Rheumatoid arthritis (RA) FLS were stimulated with different stimuli (T: Tumour necrosis factor (TNF) $10 \mathrm{ng} / \mathrm{mL}$, IL1: IL1 $32 \mathrm{ng} / \mathrm{mL}$; P: PDGF $10 \mathrm{ng} / \mathrm{mL}$, E: epithelial growth factor (EGF) $100 \mathrm{ng} / \mathrm{mL}$, L: LPS $1 \mu \mathrm{g} / \mathrm{mL}$ ) for 36 hrs and ChoK $\alpha$ expression was determined my WB. (B) ${ }^{T}$ HMRS spectra of choline-containing metabolites from one representative RA FLS after TNF $10 \mathrm{ng} / \mathrm{mL}$ and PDGF $10 \mathrm{ng} / \mathrm{mL}$ stimulation. Quantification of choline-containing metabolites (methyl proton resonances) from 5 RA FLS lines after PDGF (C) and TNF (D) stimulation. (E) A RA FLS cell line was cultured in 10\% FBS/DMEM and MN58b $(5 \mu \mathrm{M})$ or PBS was added for $24 \mathrm{~h}$ after reaching $70 \%$ of confluence, ${ }^{1} \mathrm{HMRS}$ spectra of choline-containing metabolites (methyl proton resonances) and (F) their quantification from 5 RA FLS are shown. (G) FLS were cultured in the presence of PDGF $(10 \mathrm{ng} / \mathrm{mL})$ with or without pretreatment with MN58b $(100 \mathrm{nM}, 500 \mathrm{nM}, 1 \mu \mathrm{M}$ and $5 \mu \mathrm{M})$ for 3 days. Cellular viability was determined on day 3 using an MTT assay. Each treatment condition was performed in triplicate. (H) FLS were cultured in the presence of PDGF (10 ng/mL) with or without pretreatment with MN58b (1 and $5 \mu \mathrm{M})$ for 3 days. Cellular proliferation was determined on day 6 using a BrdU assay. Each treatment condition was performed in triplicate. (I) FLS were cultured for $48 \mathrm{~h}$ in the presence of PDGF (10 ng/mL) with or without pretreatment with PBS (P), the pan PI3K INK631 $(1 \mu \mathrm{M})(\mathrm{I})$ or MN58b (5 $\mu \mathrm{M})(\mathrm{M})$ and cyclinD1, phospho-Rb and Rb expression were determined by WB. DMEM, Dulbecco's Modified Eagle's Medium; ' ${ }^{\mathrm{HMRS}}{ }^{1} \mathrm{H}$ magnetic resonance spectroscopy; LPS, lipopolysaccharide; MTT, Methyl Thiazolyl Tetrazolium; PBS, phosphate buffered saline; WB, Western Blot. 
experiments. $^{18} 2033$ MN58b inhibits proliferation of cancer cells in vitro with an $\mathrm{IC}_{50}$ of $1-10 \mu \mathrm{M}$, and displays therapeutic activity against human tumour xenografts in vivo. ${ }^{20} 33$ After incubating RA FLS with MN58b using a dose chosen based on previous reports $(5 \mu \mathrm{M})$, levels of PCho decreased and GPC/ PCho ratio increased, further suggesting the role of ChoK $\alpha$ in choline metabolism in FLS (figure 3E, F). As ChoK $\alpha$ is involved in tumour cell proliferation, we then determined whether ChoK $\alpha$ inhibition interferes with FLS cell growth in vitro. RA FLS were pretreated with MN58b at various concentrations and then cultured in the presence of PDGF for 3 days or 6 days for Methyl Thiazolyl Tetrazolium (MTT) assay and BrdU assay, respectively. MN58b significantly decreased cell viability (figure $3 \mathrm{G}$ ) and cell proliferation (figure $3 \mathrm{H}$ ) growth in a concentration-dependent manner. This effect was most likely due to a reduced cell proliferation because there was no change in apoptosis in the MN58b-treated cells, as determined by release of histone-associated DNA fragments (see online supplementary figure S1A). We also examined the effect of the ChoK $\alpha$ inhibitor on G1 phase cell cycle regulators, comparing the effect of MN58b with a panPI3K inhibitor (INK631) that has been shown to inhibit cell proliferation as well. As shown in figure 3I, $\mathrm{MN} 58 \mathrm{~b}$ impaired the increase in phospho-Rb and cyclinD1 after PDGF stimulation to a greater extent than the panPI3K inhibitor, suggesting that cells were arrested in G0/G1. Partial silencing of ChoK $\alpha$ levels by siRNA (60\%), only slightly abolished the effect on cell cycle regulation, suggesting that low levels of ChoK $\alpha$ activity might be sufficient to maintain a proliferative phenotype in these cells as MN58b renders a much more potent reduction of ChoK activity in several cell systems than the reduction achieved by siRNA. ${ }^{20} 33$

\section{ChoKo regulates $\mathrm{p}$-AKT and $\mathrm{p}$-MAPK activation, MMP expression, migration and cell survival}

Selective inhibition of ChoK $\alpha$ attenuates MAPK and PI3K/AKT signalling in tumour cells. ${ }^{30} 31$ These pathways also regulate synoviocyte function in RA FLS. ${ }^{34}$ Figure $4 \mathrm{~A}$ shows that phosphorylation of AKT (ser473, but not thr308), and ERK1/2, were markedly reduced by ChoK $\alpha$ inhibition in FLS. MN58b also decreased the expression of several MMP after TNF stimulation (figure 4B) and reduced cell migration in a migrationscratch assay (figure 4C, D). We finally evaluated whether $\mathrm{ChoK} \alpha$ inhibition induces oxidative stress-induced apoptosis. FLS were challenged with $0.3 \mathrm{mM} \mathrm{H}_{2} \mathrm{O}_{2}$, which are conditions that induce apoptosis rather than necrosis. Pretreatment with MN58b $(5 \mu \mathrm{M})$ induced more apoptotic cell death after $\mathrm{H}_{2} \mathrm{O}_{2}$
A

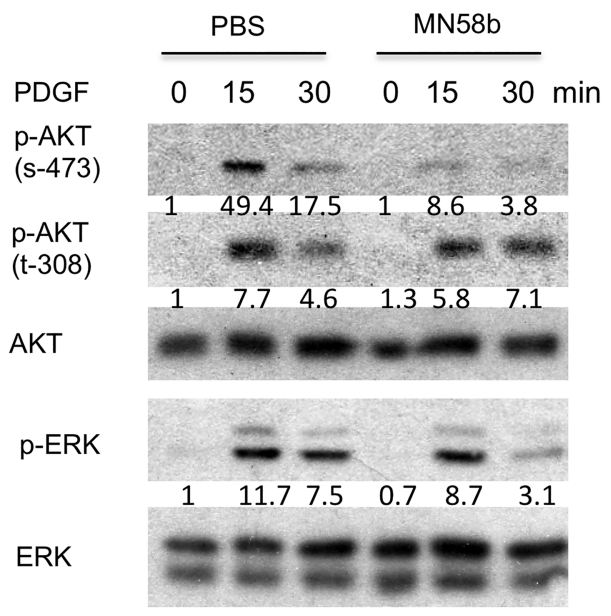

C
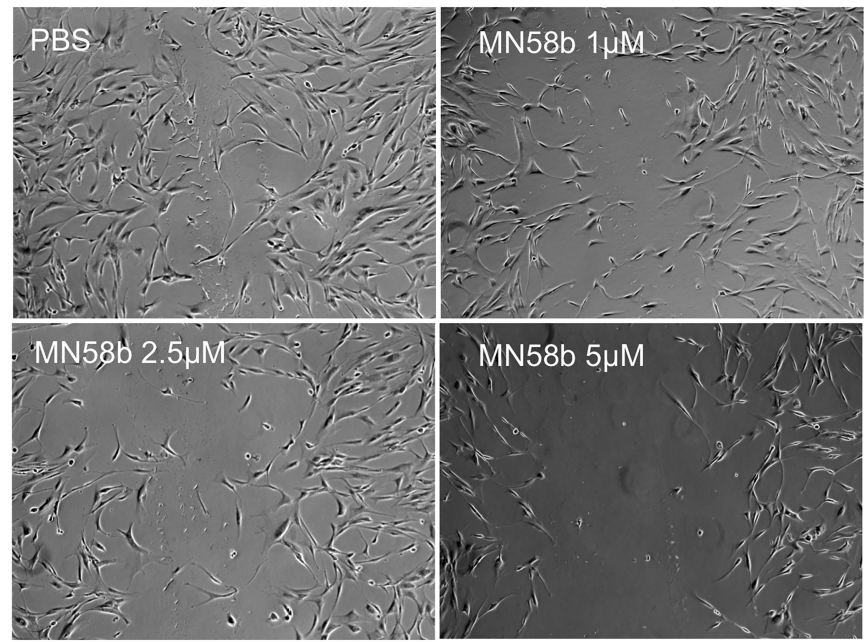

B
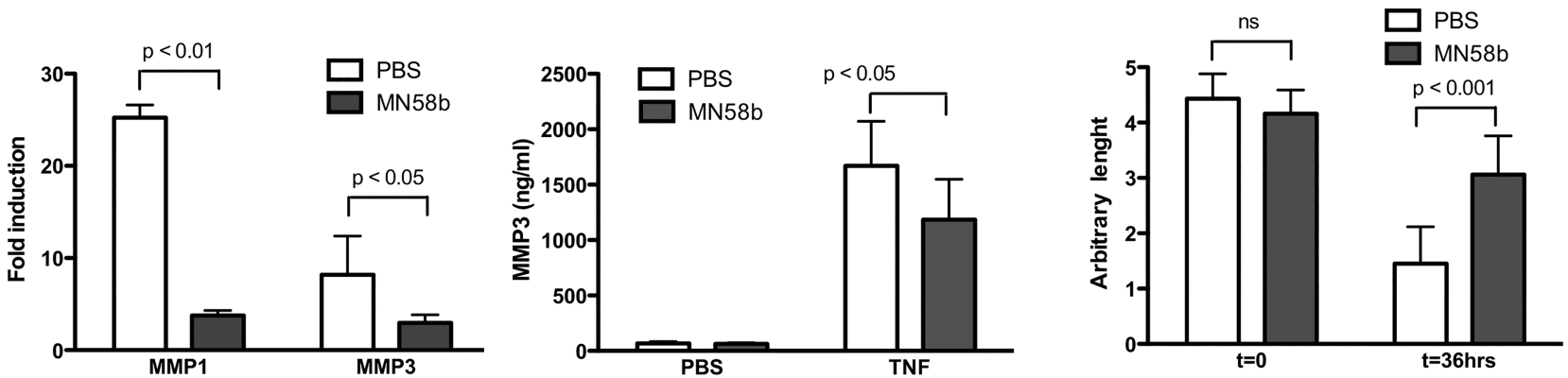

Figure 4 Choline kinase (ChoK $\alpha$ ) regulates p-AKT and p-mitogen-activated protein kinase (MAPK) activation, cytokine expression and migration. (A) Fibroblast-like synoviocytes (FLS) were cultured in the presence of platelet derived growth factor (PDGF) (10 ng/mL) with or without pretreatment with MN58b $(5 \mu \mathrm{M})$. Lysates of rheumatoid arthritis (RA) FLS were prepared when indicated after PDGF stimulation and were analysed for the expression of the indicated proteins. (B) RNA isolation of RA FLS and supernatant were prepared after $24 \mathrm{~h}$ of tumour necrosis factor stimulation and were analysed for the expression MMP1 and MMP3 by qPCR and secretion of MMP3 by ELISA. (C) FLS were grown to a confluent monolayer in 6 -well plates, and the wounded area was generated with $1 \mathrm{~mL}$ micropipette tip. Cells were then grown in the presence of PDGF (10 ng/ml) and with different MN58b concentrations. Pictures were taken after $36 \mathrm{~h}$. (D) After the wounded area was generated, cells were grown in the presence of PDGF $(10 \mathrm{ng} / \mathrm{mL})$ and MN58b $(5 \mu \mathrm{M})$. Shown quantification of migrated area (as the average of relative length between margins in 3 different fields from 3 different RA FLS cell lines). Representative of 3 different experiments. 
challenge in RA FLS (see online supplementary figure S1B-D). ChoK $\alpha$ inhibition also sensitised the FLS to $\mathrm{H}_{2} \mathrm{O}_{2}$-induced apoptosis in a dose $(0.15 \mathrm{mM})$ that does not normally induce cell death (see online supplementary figure S1E). Taken together, these findings suggest that ChoK $\alpha$ regulates multiple FLS functions downstream of cytokines, such as PDGF and TNF.

\section{ChoKa inhibition decreases severity of inflammatory arthritis in mice}

We determined whether MN58b affects arthritis severity in the $\mathrm{K} / \mathrm{BxN}$ passive serum transfer model, which is dependent on innate but not adaptive immunity. ${ }^{35}$ Based on protocols used in oncology, we injected the inhibitor daily for the first 5 days after administration of arthritogenic serum. As shown in figure $5 \mathrm{~A}$, MN58b-treated mice had significantly lower clinical scores from day 2. Histopathological analysis at day 7 showed markedly reduced inflammatory cell infiltration, joint destruction and cartilage damage in MN58b-treated mice compared with vehicletreated controls (figure 5B). Confirming functional inhibition of ChoK $\alpha$ in the joints, ${ }^{1}$ HMRS of joint extracts showed increased PCho in arthritic joints that was abrogated in MN58b-treated joints (figure 5C, D). Importantly, MN58b treatment prevented the onset of arthritis and also successfully suppressed joint swelling in mice if treatment was initiated in established disease (figure 5E). To evaluate the influence of ChoK $\alpha$ inhibition on synovial inflammatory mediators, we determined relative expression of selected genes and protein levels of selected cytokines in joints from these mice on day 7 after serum transfer. mRNA for IL-1 $\beta$, IL-6, MMP3 and MMP13 were significantly lower in MN58b-treated mice (figure 6A). ELISA analysis confirmed the reduction of IL- $1 \beta$ and IL- 6 in MN58b-treated joints (figure 6B). WB analysis of joint extracts from a second group of mice on day 5 after $\mathrm{KxB} / \mathrm{N}$ sera injection (day 5 scores were $11.75 \pm 1$ and $5.5 \pm 0.5, \mathrm{p}<0.01)$ also showed decreased phosphorylation of AKT and ERK in MN58b-treated mice (figure 6C, D). ChoK $\alpha$ expression was similar in control and phosphate buffered saline (PBS) or MN58b-treated arthritic joints (figure 6C).

\section{DISCUSSION}

In this study, we identified $\mathrm{ChoK} \alpha$ as a potential therapeutic target in RA FLS that could contribute to the aggressive phenotype of these cells in vivo. Importantly, ChoK $\alpha$ inhibition by a selective small molecule decreased FLS migration and proliferation as well as abrogated joint inflammation and damage in a murine model of RA. Small molecule inhibitors that inhibit key signalling molecules in RA have the potential to improve efficacy and to overcome some limitations of antibody-based therapeutic approaches, such as parental treatment and cost. ${ }^{36-38}$ Based on these data, we propose that inhibiting ChoK $\alpha$ could complement current RA therapies by suppressing pathogenic FLS behaviour. Although ChoK $\alpha$ inhibitors could potentially target other cell types, current studies only assesses their effect on FLS.
A

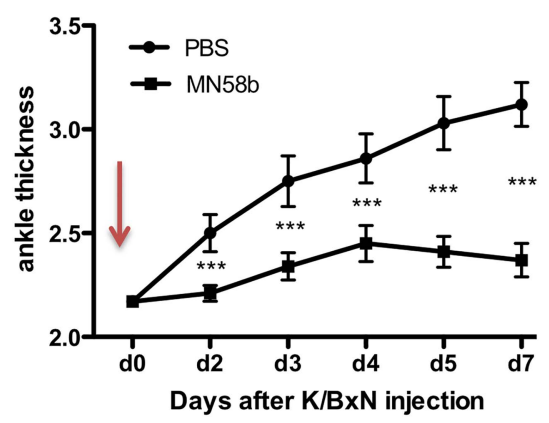

C

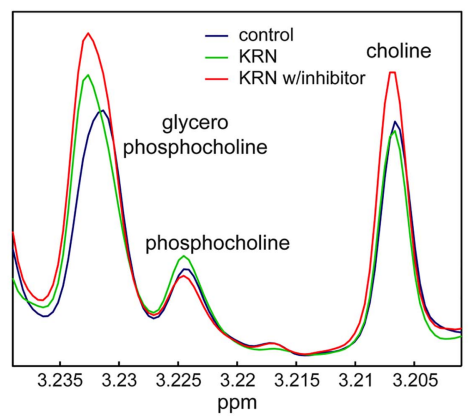

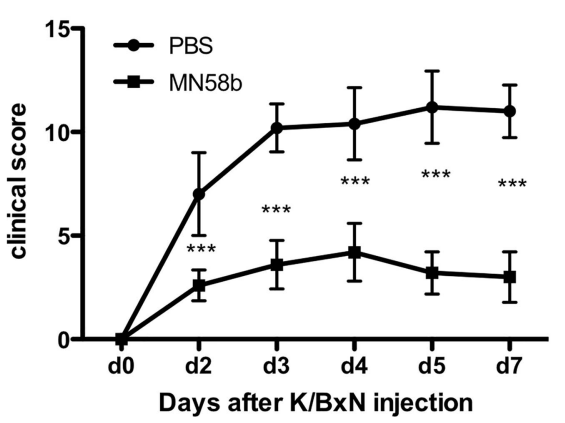

D

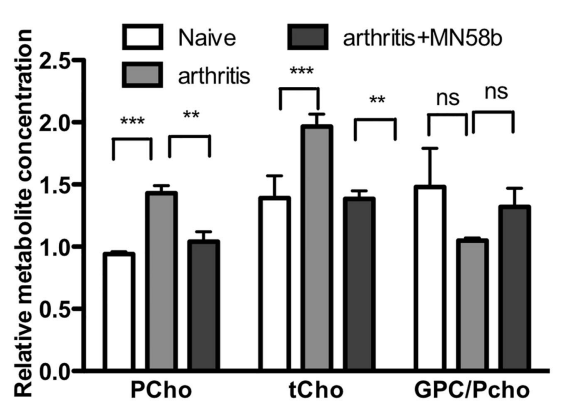

$\mathrm{B}$

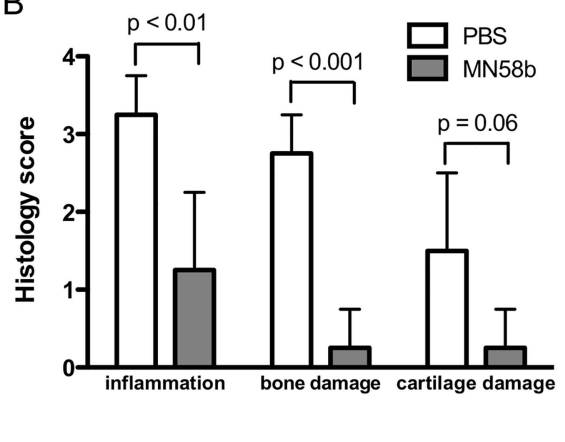

$\mathrm{E}$

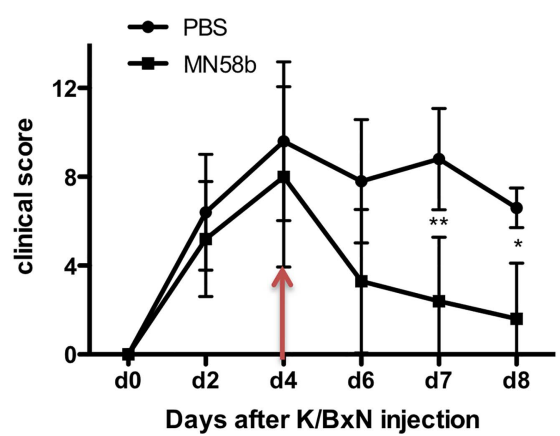

Figure 5 Choline kinase $(\mathrm{ChoK} \alpha)$ inhibition treatment successfully abrogated joint inflammation and destruction. WT mice were injected with $150 \mu \mathrm{L}$ serum from adult K/BxN mice on day 0 . MN58b was administrated every day from day 0 to 5 at $3 \mathrm{mg} / \mathrm{kg}$. (A) Ankle thickness and clinical score in PBS-treated animals (black circles, $n=5$ ) and MN58b-treated animals (black squares, $n=5$ ) injected with $150 \mu \mathrm{L}$ of $K / B \times N$ serum on day 0 . Values are mean \pm SD. ${ }^{* *}=p<0.001$. (B) Histological scores for joint inflammation, erosion and cartilage damage in PBS-treated and MN58b-treated mice (5 mice/group) on day 7 after serum transfer. (C) Representative ${ }^{1} \mathrm{HMRS}$ spectra (methyl proton resonances of choline-containing metabolites) and (D) quantification of choline-containing metabolites in joints from naive and arthritic joints at day 7 with or without daily MN58b treatment. (E) WT mice were injected with $150 \mu \mathrm{L}$ serum from adult K/BxN mice on day 0 . MN58b was administrated every day from day 4 to 7 at $3 \mathrm{mg} / \mathrm{kg}$. Shown clinical score in PBS-treated animals (black circles, $n=5$ ) and MN58b-treated animals (black squares, $n=5$ ). Values are means $\pm S D$. * $p<0.05$, ${ }^{* *} \mathrm{p}<0.01$. ${ }^{1} \mathrm{HMRS},{ }^{1} \mathrm{H}$ magnetic resonance spectroscopy; PBS, phosphate buffered saline; WT, wild type. 
A
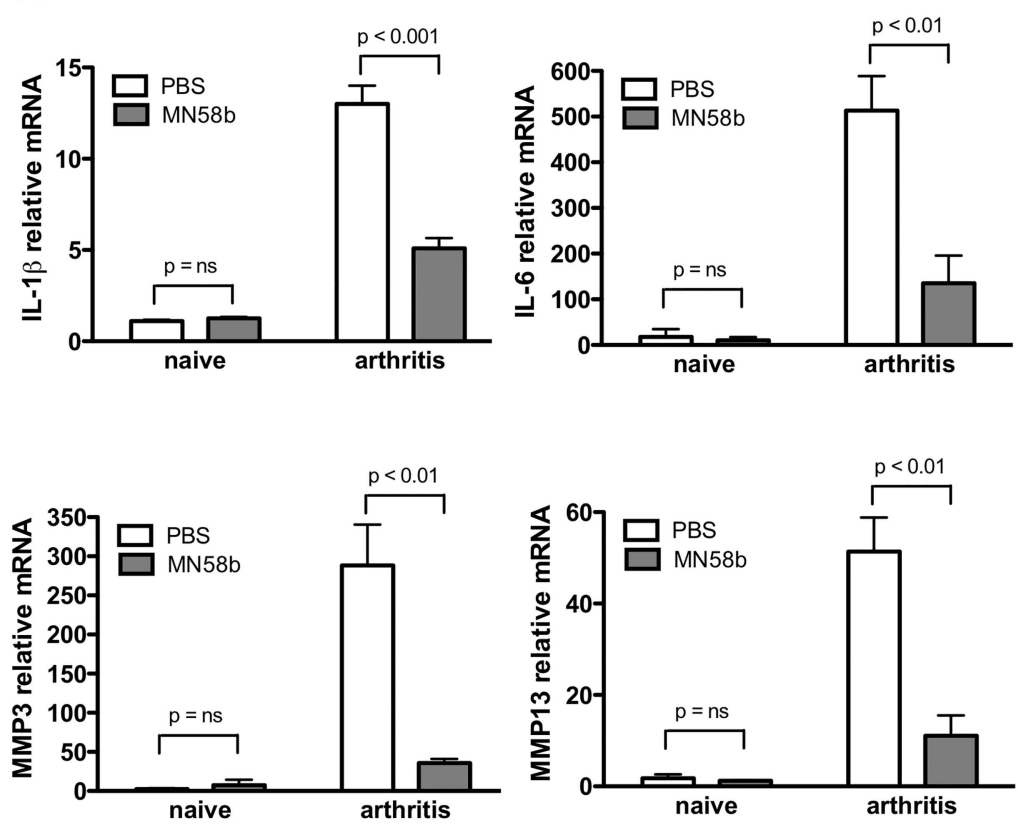

B

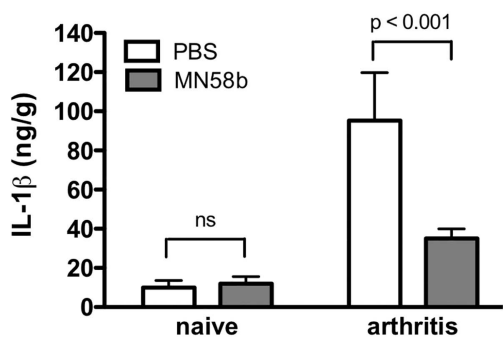

C

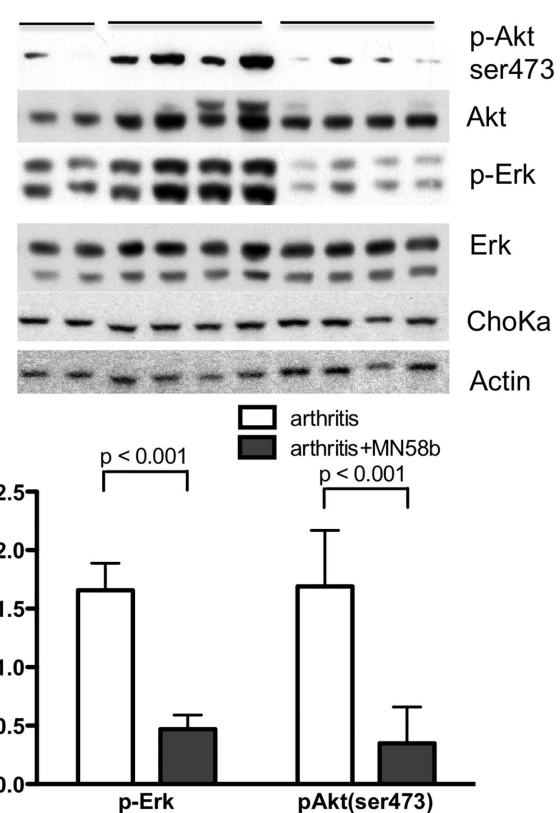

Figure 6 Choline kinase $(\mathrm{ChoK} \alpha)$ inhibition treatment decreases inflammatory mediators in the KxB/N model. (A) PBS and MN58b-treated WT mice were injected with $150 \mu \mathrm{L}$ of $\mathrm{K} / \mathrm{BxN}$ serum on day 0 and they were sacrificed at day 7 . Clinical scores at day 7 were $11 \pm 1.2$ and $3 \pm 1.2$, respectively $(p<0.001)$. RNA isolation of naive and arthritic joints at day 7 with or without daily MN58b treatment, were prepared and analysed for the expression of the indicated genes. Results are expressed as means of 4 mice/group \pm SD. (B) PBS and MN58b-treated WT mice were injected with $150 \mu \mathrm{L}$ of $\mathrm{K} / \mathrm{BxN}$ serum on day 0 and they were sacrificed at day 5 . Clinical scores at day 5 were $11.75 \pm 1$ and $5.5 \pm 0.5$, respectively ( $<<0.01$ ). Joint protein from naive and arthritic mice of PBS and MN58b-treated mice was extracted and analysed by ELISA and (C) by WB for the presence of the indicated proteins. (D) Quantitative analysis of western blots (arbitrary densitometry units) after normalising results to total protein. PBS, phosphate buffered saline; WB, Western Blot; WT, wild type.

Many signalling pathways activated under inflammatory and hypoxic conditions have profound effects on cellular metabolism to support cell growth and survival. The study of cancer cell metabolism has successfully identified cancer-specific metabolic changes that provide new therapeutic targets. Other cell types, for instance, lymphocytes are subject to major metabolic challenges upon activation and, therefore, adopt specific metabolic programmes to adapt to changing environmental conditions. ${ }^{39} 40$ However, there are little data about targeting the metabolome in non-cancer conditions ${ }^{41}$ or regarding metabolic changes in FLS. We postulate, based on our results, that ChoK $\alpha$ and choline metabolism are activated in inflamed joints, and that targeting the metabolome can be a new treatment strategy in inflammatory diseases. Although much is known about the role of ChoK $\alpha$ in tumorigenesis and cancer cell proliferation, very little information is available about its activity in normal cells or inflammatory diseases. ${ }^{25-29}$ Although $\mathrm{ChoK} \alpha$ silencing induced a decrease of proliferation in osteoblast, ${ }^{28}$ no effect in proliferation was observed in endothelial cells. ${ }^{29}$ Yet, FLS must meet the bioenergetic and biosynthetic demands of increased cell proliferation and adapt to changing environmental conditions in which nutrients and oxygen might be limited, ${ }^{42}$ and also enriched with apoptosis-inducing factors, such as oxygen radicals, nitric oxide and cytokines. Interestingly, choline-containing metabolites profile in pulmonary fibroblasts suggests ChoKo activation in other types of fibroblasts, and could potentially play a role in other inflammatory disorders.

We did not detect differences in ChoK $\alpha$ activity between RA and OA samples. Although this could be due to the mixture of cell types in synovial samples, PCho was the predominant metabolite in cultured normal, OA and RA FLS indicating that this pathway is intrinsically important in FLS metabolism and is essential for FLS pathogenic functions under proinflammatory stimulation, and might act at different levels (see online supplementary figure S2). ChoK $\alpha$ inhibition alters downstream effectors such as PtdCho, which can be considered as a source of lipid second messengers since it generates phosphatidic acid, diacylglycerol and lysophosphatidic acid. ${ }^{14}$ In addition to these pathways, inhibition of ChoK $\alpha$ affects signalling pathways such as AKT and ERK in several cell systems. ${ }^{30}{ }^{31}$ Our results demonstrate that, ChoK $\alpha$ inhibition in FLS is a potent modulator of these signalling pathways, blocks phosphorylation of $\mathrm{Rb}$, suppresses production of cyclin $\mathrm{D} 1$, and interferes with cell activation by interleukins and PDGF, in keeping with previous results in other cell systems. ${ }^{43}$ 
We also show that inhibiting this pathway suppresses inflammatory arthritis in the passive $\mathrm{KxB} / \mathrm{N}$ model. This model is dependent on FLS $^{44}$ as well as other innate immune cell types, such as macrophages, neutrophils and mast cells. Unfortunately, CHKA-deficiency is embryonic-lethal and $\mathrm{CHKA}^{\mathrm{F} / \mathrm{F}}$ mice are not available to study in the specific cell types that confer protection from arthritis. Although most of these studies are focused in the ChoK $\alpha 1$ isoform, the recent discovery of the human $\mathrm{ChoK} \beta$ isoform raises the possibility that this newly identified kinase might also be relevant. However, ChoK $\beta$ activation was not able to induce tumour growth under conditions, while ChoK $\alpha 1$ does. ${ }^{45}{ }^{46}$ Furthermore MN58b showed a much higher specificity against ChoK $\alpha 1\left(\mathrm{IC}_{50}=5 \mu \mathrm{M}\right)$ than against ChoK $\beta$ $\left(\mathrm{IC}_{50}=107.5 \mu \mathrm{M}\right)$, this is 21.5 times more potent against ChoK $\alpha 1$ than ChoK $\beta$ isoform. ${ }^{46}$ These observations suggest that the effect we detect is mostly through ChoK $\alpha$.

Unique metabolomic profiles have been identified in the serum of patients with several diseases. For instance, the serum metabolic fingerprint in established RA was clearly different from that of healthy controls. ${ }^{10}$ Lactate and lipids were important discriminators of inflammatory burden. Of interest, a number of metabolites, such as choline, were also found to contribute strongly to the correlation. Other studies have also determined changes in phospholipid metabolites in serum of RA patients. ${ }^{9}$ The phospholipid composition of the synovial fluid (SF) has also been recently described. ${ }^{47}$ SF from patients with RA had higher content of total phospholipids, major phospholipid classes and phospholipid species than control SF. These data suggest altered phospholipid metabolism in RA and that cells such as FLS, which mediate the synthesis and release of phospholipids, ${ }^{48}$ increase their production and modify their classes under inflammation.

Taken together, our in vitro and in vivo studies suggest that choline metabolism is activated in RA FLS under pro-inflammatory conditions, and that selectively blocking ChoK $\alpha$ might be beneficial in inflammatory arthritis by suppressing FLS functions, including migration and resistance to apoptosis. Therefore, the data provide a rationale for strategies that inhibit ChoK $\alpha$ as a therapeutic approach in RA.

\section{MATERIAL AND METHODS}

Mice

KRN T-cell receptor transgenic mice were a gift from Dr D Mathis and Dr C Benoist (Harvard Medical School, Boston, Massachusetts, USA) and Institut de Génétique et de Biologie Moléculaire et Cellulaire (Strasbourg, France). Mice were on the $\mathrm{C} 57 \mathrm{Bl} / 6$ background. Mice used in these experiments were 8-12 weeks old. All animal protocols received advance approval by the institutional review board, and follow the National Institute of Health (NIH) Guide for the Care and Use of Laboratory Animals.

\section{Reagents}

MN58b (1,4-(4-4'-Bis-((4-(dimethylamine)pyridinium-1-yl) methyl $\}$ diphenyl) butane dibromide) was obtained from JCL. MN58b inhibits proliferation of cancer cells in vitro with an $\mathrm{IC}_{50}$ of $1-10 \mu \mathrm{M}$, and its specificity has been addressed in previous reports. $^{20} 4349$ INK631, a pan PI3K inhibitor was obtained from Intellikine (La Jolla, California, USA). Concentrations for MN58b and INK631 were chosen based on previous reports. Cytokines and PDGF-BB were obtained from R\&D Laboratories (Minneapolis, Minnesota, USA).

\section{Preparation of synovium and synoviocytes, and cell lines}

Synovium and FLS were obtained from patients undergoing total joint replacement or synovectomy who meet the 1987 revised American College of Rheumatology criteria for seropositive RA or patients with $\mathrm{OA}$ as previously described. ${ }^{50-52}$ Human pulmonary fibroblasts (HPF) cell line was obtained from ScienceCell Research Laboratories. I90, 14D7 and GM0321B cell lines were donated by Ben Yu's laboratory.

\section{Choline-containing metabolites profiling using ${ }^{1} \mathrm{HMRS}$}

RA and OA FLS and synovium were isolated and prepared for the ${ }^{1}$ HMRS analyses as described. ${ }^{53}{ }^{54}$ MRS spectra were acquired at $16.4 \mathrm{~T}(700 \mathrm{MHz})$ on a Bruker Avance spectrometer (Bruker BioSpin, Billerica, Massachusetts, USA) equipped with a TCI cryoprobe and high-throughput robotics. One-dimensional ${ }^{1}$ HMRS spectra were acquired using at least 512 scans and 8 dummy scans, $32 \mathrm{~K}$ data points, and a spectral width of $9.8 \mathrm{kHz}$. Excitation sculpting pulse sequence was implemented to suppress the water signal. All the MRS datasets were processed using MetaboLab ${ }^{55}$ in the MATLAB programming environment (MathWorks, Natick, Massachusetts, USA). MRS spectra were normalised based on the probabilistic quotient normalisation method. ${ }^{56}$ Assignment of MRS resonances and metabolite quantification were performed using Chenomx nuclear magnetic resonance (NMR) Suite and other available databases. ${ }^{57-59}$ For clarity, only the choline-containing metabolite resonances generated by the methyl protons of PCho, GPC and Cho (MRS spectral region between 3.20 and $3.24 \mathrm{ppm}$ ) are shown in the figures. We quantified the metabolite concentrations of intracellular fibroblast cell lines and synovium tissue extracts, and the results are presented as relative concentrations of choline-containing metabolites. Ratio of choline-containing metabolites (PCho/total choline and GPC/PCho) are also included.

\section{Statistical analysis}

Data are expressed as means \pm SD. The analysis used unpaired Student's t test for comparing two groups, and analysis of variance (ANOVA) for multiple group comparisons. Results were considered significant if $\mathrm{p}<0.05$.

Acknowledgements This work was supported by grants from the National Institutes of Arthritis and Musculoskeletal and Skin (MG: 1K08AR064834), the National Institute of Allergy and Infectious Diseases (GSF; 2R01Al070555) and Ministerio de Economía y Competitividad (JCL: SAF2011-29699, RD12/0036/0019). Support for the NMR facility was provided by the University of Texas Health Science Center at San Antonio (UTHSCSA) and National Institutes of Health Grant NCI P30 CA54174 (CTRC at UTHSCSA).

Contributors MG and ES-L designed the project, performed most of the experiments and analysed the data. MG also wrote the manuscript. AL and ST performed and interpreted MRS analysis. RG-C performed IHC staining. MK helped to interpret the data and in manuscript preparation. JCL provided MN58b, participated in the design of some experiments, helped to interpret the data and in manuscript preparation. GSF designed the study, analysed the data, supervised the overall project and wrote the manuscript.

Competing interests MG, ES-L, ST, JCL, MK and GSF have filed a patent application.

Provenance and peer review Not commissioned; externally peer reviewed.

\section{REFERENCES}

1 Firestein GS. Evolving concepts of rheumatoid arthritis. Nature 2003;423:356-61.

2 Bartok B, Firestein GS. Fibroblast-like synoviocytes: key effector cells in rheumatoid arthritis. Immunol Rev 2010;233:233-55.

3 Bottini N, Firestein GS. Duality of fibroblast-like synoviocytes in RA: passive responders and imprinted aggressors. Nat Rev Rheumatol 2013;9:24-33.

4 Lefevre S, Knedla A, Tennie C, et al. Synovial fibroblasts spread rheumatoid arthritis to unaffected joints. Nature medicine 2009;15:1414-20.

5 Eckhart AD, Beebe K, Milburn M. Metabolomics as a key integrator for "omic" advancement of personalized medicine and future therapies. Clin Trans/ Sci 2012;5:285-8.

6 Hugle T, Kovacs $H$, Heijnen IA, et al. Synovial fluid metabolomics in different forms of arthritis assessed by nuclear magnetic resonance spectroscopy. Clin Exp Rheumatol 2012;30:240-5. 
7 Lauridsen MB, Bliddal H, Christensen R, et al. 1H NMR spectroscopy-based interventional metabolic phenotyping: a cohort study of rheumatoid arthritis patients. J Proteome Res 2010;9:4545-53.

8 Madsen RK, Lundstedt T, Gabrielsson J, et al. Diagnostic properties of metabolic perturbations in rheumatoid arthritis. Arthritis Res Ther 2011;13:R19.

9 Priori R, Scrivo R, Brandt J, et al. Metabolomics in rheumatic diseases: the potentia of an emerging methodology for improved patient diagnosis, prognosis, and treatment efficacy. Autoimmun Rev 2013;12:1022-30.

10 Young SP, Kapoor SR, Viant MR, et al. The impact of inflammation on metabolomic profiles in patients with arthritis. Arthritis Rheum 2013;65:2015-23.

11 Casado-Vela J, Cebrian A, Gomez del Pulgar MT, et al. Approaches for the study of cancer: towards the integration of genomics, proteomics and metabolomics. Clin Trans/ Oncol 2011;13:617-28.

12 DeBerardinis RJ, Lum JJ, Hatzivassiliou G, et al. The biology of cancer: Metabolic reprogramming fuels cell growth and proliferation. Cell Metab 2008;7:11-20.

13 Hsu PP, Sabatini DM. Cancer cell metabolism: Warburg and beyond. Cell 2008:134:703-07.

14 Glunde K, Bhujwalla ZM, Ronen SM. Choline metabolism in malignant transformation. Nat Rev Cancer 2011:11:835-48.

15 Glunde K, Jie C, Bhujwalla ZM. Molecular causes of the aberrant choline phospholipid metabolism in breast cancer. Cancer Res 2004;64:4270-6.

16 Iorio E, Mezzanzanica D, Alberti P, et al. Alterations of choline phospholipid metabolism in ovarian tumor progression. Cancer Res 2005;65:9369-76.

17 Romanska HM, Tiziani S, Howe RC, et al. Nuclear Magnetic Resonance Detects Phosphoinositide 3-Kinase/Akt-Independent Traits Common to Pluripotent Murine Embryonic Stem Cells and Their Malignant Counterparts. Neoplasia 2009;11:1301.

18 Lacal JC. Choline kinase: a novel target for antitumor drugs. IDrugs 2001:4:419-26.

19 Glunde K, Jiang L, Moestue SA, et al. MRS and MRSI guidance in molecular medicine: targeting and monitoring of choline and glucose metabolism in cancer. NMR Biomed 2011;24:673-90.

20 Rodriguez-Gonzalez A, Ramirez de Molina A, Fernandez F, et al. Inhibition of choline kinase as a specific cytotoxic strategy in oncogene-transformed cells. Oncogene 2003;22:8803-12.

21 Ramirez de Molina A, Gutierrez R, Ramos MA, et al. Increased choline kinase activity in human breast carcinomas: clinical evidence for a potential novel antitumor strategy. Oncogene 2002;21:4317-22.

22 Ramirez de Molina A, Rodriguez-Gonzalez A, Gutierrez R, et al. Overexpression of choline kinase is a frequent feature in human tumor-derived cell lines and in lung, prostate, and colorectal human cancers. Biochem Biophys Res Commun 2002;296:580-3.

23 Ramirez de Molina A, Sarmentero-Estrada J, Belda-Iniesta C, et al. Expression of choline kinase alpha to predict outcome in patients with early-stage non-small-cell lung cancer: a retrospective study. Lancet Oncol 2007;8:889-97.

24 Li M, Peng Z, Liu Q, et al. Value of 11C-choline PET/CT for lung cancer diagnosis and the relation between choline metabolism and proliferation of cancer cells. Oncol Rep 2013:29:205-11.

25 Zimmerman T, Moneriz C, Diez A, et al. Antiplasmodial Activity and Mechanism of Action of RSM-932A, a Promising Synergistic Inhibitor of Plasmodium falciparum Choline Kinase. Antimicrob Agents Chemother 2013;57:5878-88.

26 Cuadrado A, Carnero A, Dolfi F, et al. Phosphorylcholine: a novel second messenger essential for mitogenic activity of growth factors. Oncogene 1993;8:2959-68.

27 Jimenez B, del Peso L, Montaner S, et al. Generation of phosphorylcholine as an essential event in the activation of Raf-1 and MAP-kinases in growth factors-induced mitogenic stimulation. J Cell Biochem 1995;57:141-9.

28 Li Z, Wu G, van der Veen JN, et al. Phosphatidylcholine metabolism and choline kinase in human osteoblasts. Biochim Biophys Acta 2014;1841:859-67.

29 Mori N, Gadiya M, Wildes F, et al. Characterization of choline kinase in human endothelial cells. NMR Biomed 2013;26:1501-7.

30 Yalcin A, Clem B, Makoni S, et al. Selective inhibition of choline kinase simultaneously attenuates MAPK and PI3K/AKT signaling. Oncogene 2010;29:139-49.

31 Chua BT, Gallego-Ortega D, Ramirez de Molina A, et al. Regulation of Akt(ser473) phosphorylation by choline kinase in breast carcinoma cells. Mol Cancer 2009;8:131.

32 Glunde K, Bhujwalla ZM. Metabolic tumor imaging using magnetic resonance spectroscopy. Semin Oncol 2011;38:26-41.

33 Hernandez-Alcoceba R, Fernandez F, Lacal JC. In vivo antitumor activity of choline kinase inhibitors: a novel target for anticancer drug discovery. Cancer Res 1999;59:3112-18.
34 Bartok B, Boyle DL, Liu Y, et al. PI3 kinase delta is a key regulator of synoviocyte function in rheumatoid arthritis. Am J Pathol 2012;180:1906-16.

35 Kyburz D, Corr M. The KRN mouse model of inflammatory arthritis. Springer Semin Immunopathol 2003;25:79-90.

36 Kremer JM, Bloom BJ, Breedveld FC, et al. The safety and efficacy of a JAK inhibitor in patients with active rheumatoid arthritis: Results of a double-blind, placebo-controlled phase lla trial of three dosage levels of CP-690,550 versus placebo. Arthritis Rheum 2009:60:1895-905.

37 Sweeney SE, Firestein GS. Primer: signal transduction in rheumatic disease--a clinician's guide. Nat Clin Pract Rheumatol 2007;3:651-60.

38 Weinblatt ME, Kavanaugh A, Burgos-Vargas R, et al. Treatment of rheumatoid arthritis with a Syk kinase inhibitor: a twelve-week, randomized, placebo-controlled trial. Arthritis Rheum 2008:58:3309-18.

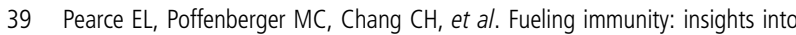
metabolism and lymphocyte function. Science 2013;342:1242454.

40 Wang R, Green DR. Metabolic checkpoints in activated T cells. Nat Immunol 2012;13:907-15.

41 McDonald G, Deepak S, Miguel L, et al. Normalizing glycosphingolipids restores function in CD4+ T cells from lupus patients. J Clin Invest 2014:124:712-24.

42 Gaber T, Dziurla R, Tripmacher R, et al. Hypoxia inducible factor (HIF) in rheumatology: low 02! See what HIF can do! Ann Rheum Dis 2005;64:971-80.

43 Ramirez de Molina A, Gallego-Ortega D, Sarmentero-Estrada J, et al. Choline kinase as a link connecting phospholipid metabolism and cell cycle regulation: implications in cancer therapy. Int J Biochem Cell Biol 2008;40:1753-63.

44 Lee DM, Kiener HP, Agarwal SK, et al. Cadherin-11 in synovial lining formation and pathology in arthritis. Science 2007;315:1006-10

45 Gallego-Ortega D, Gomez del Pulgar T, Valdes-Mora F, et al. Involvement of human choline kinase alpha and beta in carcinogenesis: a different role in lipid metabolism and biological functions. Adv Enzyme Regul 2011;51:183-94.

46 Gallego-Ortega D, Ramirez de Molina A, Ramos MA, et al. Differential role of human choline kinase alpha and beta enzymes in lipid metabolism: implications in cancer onset and treatment. PLOS ONE 2009:4:e7819.

47 Kosinska MK, Liebisch G, Lochnit G, et al. A lipidomic study of phospholipid classes and species in human synovial fluid. Arthritis Rheum 2013:65:2323-33.

48 Schwarz IM, Hills BA. Synovial surfactant: lamellar bodies in type B synoviocytes and proteolipid in synovial fluid and the articular lining. Br J Rheumatol 1996;35:821-7.

49 Ramirez de Molina A, Banez-Coronel M, Gutierrez R, et al. Choline kinase activation is a critical requirement for the proliferation of primary human mammary epithelial cells and breast tumor progression. Cancer Res 2004;64:6732-9.

50 Alvaro-Gracia JM, Zvaifler NJ, Brown CB, et al. Cytokines in chronic inflammatory arthritis. VI. Analysis of the synovial cells involved in granulocyte-macrophage colony-stimulating factor production and gene expression in rheumatoid arthritis and its regulation by IL-1 and tumor necrosis factor-alpha. J Immunol 1991;146:3365-71.

51 Schipper RG, van den Heuvel LP, Verhofstad AA, et al. Polyamines and DNA methylation in childhood leukaemia. Biochem Soc Trans 2007;35:331-5.

52 Alvaro-Gracia JM, Zvaifler NJ, Firestein GS. Cytokines in chronic inflammatory arthritis. V. Mutual antagonism between interferon-gamma and tumor necrosis factor-alpha on HLA-DR expression, proliferation, collagenase production, and granulocyte macrophage colony-stimulating factor production by rheumatoid arthritis synoviocytes. J Clin Invest 1990;86:1790-8.

53 Tiziani S, Lodi A, Khanim FL, et al. Metabolomic profiling of drug responses in acute myeloid leukaemia cell lines. PLoS One 2009;4:e4251.

$54 \mathrm{Wu} H$, Southam AD, Hines $A$, et al. High-throughput tissue extraction protocol for NMR- and MS-based metabolomics. Analytical Biochemistry 2008;372:204-12.

55 Ludwig C, Gunther UL. MetaboLab--advanced NMR data processing and analysis for metabolomics. BMC Bioinformatics 2011;12:366

56 Dieterle F, Ross A, Schlotterbeck G, et al. Probabilistic quotient normalization as robust method to account for dilution of complex biological mixtures. Application in 1H NMR metabonomics. Anal Chem 2006:78:4281-90.

57 Psychogios N, Hau DD, Peng J, et al. The human serum metabolome. PLoS ONE 2011;6:e16957.

58 Quehenberger 0 , Armando AM, Brown AH, et al. Lipidomics reveals a remarkable diversity of lipids in human plasma. J Lipid Res 2010;51:3299-305.

59 Wishart DS, Tzur D, Knox C, et al. HMDB: the Human Metabolome Database. Nucleic Acids Res 2007;35:D521-6. 